\title{
HISTORIA Y PROCESOS DE LA CIENCIA DE LA ADMINISTRACIÓN
}

\section{Yolíma Andrea Merchán Gó́mez}

Semillera de investigación Crecer

Grupo Construyendo Comunidad Educativa

En momentos de la vida es importante conocer el desarrollo que han tenido las cosas que influyen en la vida; saber si desde su origen siguen siendo las mismas o si por el contrario a través de los tiempos han cambiado o han sufrido algunas modificaciones.

Es importante identificar que la administración al igual que todo también tiene su historia y un proceso de transformación pues es conocido que "Donde quiera que hubo acción humana para obtener algo, para lograr un fin se probo alguna forma de organización $y$ de racionalización del trabajo." ${ }^{\prime \prime}$ Es por esto que se retoman tiempos pasados donde las formas primitivas de organización familiar se toman como una práctica administrativa, pues la vida exigía una distribución de - tareas entre los integrantes que a su vez surgieron lideres que dirigían las actividades de una comunidad para la realización de diversas tareas como la caza, la pesca y la recolección de frutos, especialmente en las agrupaciones nómadas.

Para este caso es necesario conocer un poco sobre la historia de la administración y los diferentes cambios que ha sufrido a través del tiempo. Es de mi interés dar a conocer los factores más importantes de las diferentes teorías administrativas. De una manera no muy profunda a continuación se citan algunas de esos cambios significativos:

En el Antiguo Egipto se aplicaba un sistema de administración que se caracterizó por un alto grado de centralización. Podríamos deducir que en el antiguo Egipto aparecen las primeras formas de administración que surgen de la necesidad de dirigir y regular el almacenamiento, distribución y comercialización de las cosechas así como de la construcción de vías y canales para facilitar las anteriores actividades.

E Antiguo Imperio chino dejo también principios básicos de administración

"CARDONA Carlos Ramirez. "Fundamentos de Administración". Ecoe Ediciones. 1993. Pág. 77 
aplicables actualmente, por ejemplo la importancia para un gobernador de conocer la problemática de su país, buscar soluciones acordes a dichos problemas, realizar estudios a fondo, buscar el bien común y fomentar el bienestar económico del pueblo.

La función administrativa tuvo que enfrentarse a una transformación enorme de cambios tecnológicos producidos por la creciente industrialización y dejando atrás las actividades gubernamentales o manejo de problemas surgidos en el ámbito mercantil y artesanal ocupándose ahora de la mecanización de la industria y la producción a gran escala.

Henry Fayol autor de la teoría de la organización es considerado junto a Taylor como los padres de la administración científica o clásica. "Los aportes de los anteriores autores y de muchos otros que le siguieron, constituyen el comienzo de la administración como cuerpo de principio y técnicas que configuran la teoría moderna administrativa que como se ve empieza a formarse dentro del proceso de revolución industrial."

Se puede argumentar que estos autores dan gran aporte al fenómeno administrativo llamado escuela clásica o administración científica tomando como objeto el estudio científico y a su vez analizando los procesos de trabajo cómo es la organización de la empresa y llegando a conclusiones tales como que los fundamentos de la teoría administrativa actual están constituidos por pautas y proposiciones.

Posteriormente Max Weber desarrollo la teoría de la administración de burocracia que recalcaba la necesidad de una jerarquía manejada por reglamentos y líneas de autoridad las cuales definió pensando que toda organización dirigida a alcanzar metas y compuesta por miles de individuos, requería de un estrecho control de sus actividades. En su concepto la organización ideal era una burocracia con actividades y objetivos establecidos con una división de trabajo detallado. Weber pensaba que la competencia técnica tenía gran importancia en la evaluación de resultados.

Debido a que el enfoque clásico no lograba suficiente eficiencia productiva ni armonía en el centro del trabajo surgió la escuela de relaciones humanas. Esta hizo que aumentara el interés por ayudar a los gerentes a manejar con más eficacia los recursos humanos de sus organizaciones.

Luego apareció una teoría innovadora como lo es la teoría de las organizaciones donde su objetivo primordial era descubrir la limitación que tenia la racionalidad

Ibid. Pág. 151 
humana. Para esto era importante el conocimiento y la identificación de aquel ser que se comportaba con relativa racionalidad y buscaba obtener resultados satisfactorios y los diferenciaba de otros que actuaban racionalmente y buscaban maximizar el beneficio.

Estas son algunas de las teorías que han dejado grandes aportes a la administración pues en base de ellas muchas empresas han establecidos su misión, visión y objetivos.

Es importante resaltar que "los nuevos gerentes deben aceptar y sobresalir en responsabilidad de liderazgo para desempeñarse como estrategas globales, maestros en tecnologías, políticos consumados y lideres/ motivadores ${ }^{\prime \prime 3}$ EI liderazgo es tomado como un tema representativo de las nuevas tendencias de administración; estas se toman como la clave para el desempeño organización y a su vez es el punto importante para el desarrollo económico de cualquier sociedad.

En los gerentes del siglo XXI están puestas muchas expectativas futuras y en la dirección que estos hagan en la organización. Por ello es importante conocer que hace algunos años se proporciono una lista de requerimientos vitales para el buen desempeño del gerente $y$ que debido a los nuevos retos que este enfrenta se hace necesario aplicarlos en este siglo. De esta manera según John Schermerhorn, el gerente del siglo XXI debe ser:

-Estratega global para que reconozca la interconexión entre naciones, culturas y economías en la comunidad mundial y sea capaz de planear y actuar.

-Maestro en tecnología para que sienta cómodo con las altas tecnologías existentes, entienda las tendencias tecnológicas y sus implicaciones y sea capaz de aplicarlas en su provecho.

-Político consumado para que comprenda la creciente complejidad de las regulaciones gubernamentales y el ambiente legal.

- Lífer motivador para que sea capaz de atraer trabajadores altamente motivados e inspire entusiasmo al crear un clĩma de alto desempeño.

Es así como en la actualidad la administración exige un grado mayor de aprendizaje para toda la vida y a la vez da un mayor valor de cualidades de liderazgo personal.

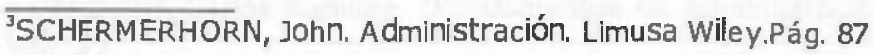


Se puede concluir que aunque se piense qua hasta ahora se está aplicando la administración y esta idea en realidad es errónea pues como se ha podido analizar esta viene de mucho antes y sus ideas provienen de raíces históricas que hoy en día se están aplicando con la única diferencia de que se busca el perfeccionamiento al aplicar nuevas tendencias de la administración y los cambios en la vida cotidiana.

\section{BIBLIOGRAFÍA}

- CERTO, Samuel. Administración Moderna. Prentice Hall, 2001

- CHIAVENATO, Idalberto. Administración. Mc Graw Hill, 2001.

- RAMIREZ, Carlos. Fundamentos de Administración. Ecoe Ediciones, 1999

- STONER, James. Administration. Prentice Hall, 1996

- SCHERMERHORN, John. Administración. Limusa Wiley, 2003

\section{EN BÚSQUEDA \\ DE LA CIENTIFICIDAD DEL TURISMO}

\section{Bibiela Mojica Tibaduiza}

Paola Carolina Gama

Grupo de Investigación para la Animación Culturạl "Muisuata"

Este artículo es un primer acercamiento al proyecto LA INVESTIGACIÓN EN TURISMO: UNA VISION DESDE LA ESCUELA DE ADMISTRACION TURISTICA Y HOTELERA (1986 - 2008) que se viene desarrollando en torno a la Tradición Investigativa en la Escuela de Administración Turística y Hotelera- EATH de la UPTC evidenciada en los trabajos de grado de los estudiantes que se han realizado desde el año 1986 hasta el 2008. Este documento abordara las siguientes temáticas, importantes para lograr el sentido de la investigación en turismo: el lugar de la investigación, la importancia del turismo, la investigación en turismo y la problemática frente a la realidad de la investigación en turismo contribuyendo a la orientación, apropiación y posibles alternativas de solución. La investigación es un lugar de conocimientos y encontrar el lugar que se merece investigar en investigación se constituye en un aspecto fundamental ya que permite develar que posición adopta la investigación en el espacio como el de la formación, el de la política entre otros. El definir el lugar de la investigación obliga a devolver las preguntas hacia las instituciones y los sujetos que investigan como, desde donde y para que investigan.

La investigación tiene capacidad de alterar lo establecido, mostrar alternativas, dislocar lo visible, revelar situaciones y procesos que estaban a la vista pero 